\title{
APAKAH PROSES PERENCANAAN PEMBANGUNAN DISNAKERTRANS KABUPATEN KULON PROGO SESUAI DENGAN UNDANG-UNDANG NO. 25 TAHUN 2004?
}

\author{
Junior Hendri Wijaya1,2 \\ ${ }^{1}$ Magister IImu Pemerintahan, STPMD, APMD, Daerah Istimewa Yogyakarta, Indonesia \\ 2Universitas Muhammadiyah Yogyakarta, Daerah Istimewa Yogyakarta, Indonesia \\ Email: Juniorhendri6@gmail.com
}

\begin{abstract}
The condition of the people of Kulon Progo Regency, has faced problems and challenges in the future, and by taking into account the strategic and potential factors possessed by the community, stakeholders, and the Regency Government, the Vision of Kulon Progo Regency is as stated in the Regional RPJP of Kulon Progo Regency 2005-2025. . The purpose of this study was to determine whether the development planning process of the Department of Manpower and Transmigration of Kulon Progo Regency is in accordance with law no. 25 of 2004. The research method used is qualitative. These results indicate that the development planning process at the Manpower and Transmigration Office of Kulon Progo Regency is in accordance with Law No. 25 of 2004, this has been proven by the initial stage process starting from the preparation of the SKPD Renstra document compiled by referring to the 2017-2022 Kulon Progo Regency RPJMD which starts from planning preparation, planning determination, controlling plan implementation; and evaluation of the implementation of the plan. However, the concrete implementation is not evenly distributed in the Kulon Progo area.
\end{abstract}

Keywords: Disnakertrans, Kulon Progo, Planning, Development, Act.

\begin{abstract}
Abstrak
Keadaan masyarakat Kabupaten Kulon Progo, telah menghadapi permasalahan dan tantangan masa depan, serta dengan memperhitungkan faktor strategis dan potensi yang dimiliki oleh masyarakat, pemangku kepentingan, serta Pemerintah Kabupaten maka Visi Kabupaten Kulon Progo seperti yang tertera dalam RPJP Daerah Kabupaten Kulon Progo Tahun 2005-2025. Tujuan penelitian ini adalah untuk mengetahui tentang apakah proses perencanaan pembangunan Dinas Tenaga Kerja dan Transmigrasi Kabupaten Kulon Progo sesuai dengan undang-undang no. 25 tahun 2004. Metode peneltian yang digunakan adalah kualitatif. Hasil ini menunjukan bahwa proses perencanaan pembangunan di Dinas Tenaga Kerja dan Transmigrasi Kabupaten Kulon Progo sudah sesuai dengan undang-undang No. 25 Tahun 2004, hal ini sudah dibuktikan dengan proses tahapan awal dimulai dari penyusunan dokumen Renstra SKPD disusun dengan mengacu RPJMD Kabupaten Kulon Progo Tahun 2017-2022 yang dimulai dari penyusunan rencana, penetapan rencana, pengendalian pelaksanaan rencana; dan evaluasi pelaksanaan rencana. Namun dalam pelaksanaan secara konkrit memang belum secara merata di daerah Kulon Progo.
\end{abstract}

Kata kunci: Disnakertrans, Kulon Progo, Perencanaan, Pembangunan, Undang-undang.

\section{PENDAhuluan}

Secara umum pengertian perencanaan adalah suatu proses yang menentukan hal yang ingin dicapai di masa mendatang yang disertai dengan tahapan-tahapan kebutuhan untuk mencapai keinginan tersebut [1]. Sementara itu, definisi pembangunan yaitu suatu proses pembangunan sebagai proses menggambarkan adanya pengembangan, baik meliputi proses pertumbuhan (growth) ataupun perubahan (change) dalam kehidupan bersama (organisasi) sosial dan budaya [2].

Undang-undang nomor 25 tahun 2004 menyebutkan perencanaan adalah suatu proses untuk menentukan tindakan masa depan yang tepat, melalui urutan pilihan, dengan memperhitungkan sumber daya yang tersedia. Selanjutnya, pembangunan nasional adalah upaya yang dilaksanakan oleh semua komponen bangsa dalam rangka 
mencapai tujuan bernegara. Bagi bangsa Indonesia, perencanaan pembangunan memiliki itu tujuan yang sangat strategis dan vital yaitu untuk menentukan arah perjalanan kehidupan bangsa ke depan [3].

Perencanaan pembangunan daerah seperti diamanatkan oleh Undang-Undang Nomor 25 Tahun2004 tentang SPPN, mewajibkan daerah untuk menyusun Rencana Pembangunan Jangka Panjang yang berdurasi waktu dua puluh tahun yang berisi tentang visi, misi dan arah pembangunan daerah. Perencanaan ini yang kemudian dijabarkan dalam Rencana Pembangunan Jangka Menengah Daerah yang berdurasi waktu lima tahun, yang memuat kebijakan keuangan daerah, strategi pembangunan daerah, kebijakan umum, program SKPD dan lintas SKPD, program kewilayahan disertai dengan rencana-rencana kerja dalam kerangka regulasi dankerangka pendanaan yang bersifat indikatif. Selanjutnya RPJM Daerah dijabarkan dalamperencanaan berdurasi tahunan yang disebut sebagai Rencana Kerja Pemerintah Daerah (RKPD)yang memuat rancangan kerangka ekonomi daerah, prioritas pembangunan daerah, rencanakerja, dan pendanaannya, baik yang dilaksanakan langsung oleh pemerintah maupun yangditempuh dengan mendorong partisipasi masyarakat.

Adapun secara garis besar bahwa setiap pemerintahan daerah memiliki perencanaan pembangunan di daerahnya masing-masing yang sudah diatur secara terpusat melalui undang-undang, begitu pun dengan pemerintahan daerah kabupaten Kulon Progo khususnya di Dinas Tenaga Kerja dan Transmigrasi atau yang disingkat dengan Disnakertrans Kabupaten Kulon Progo. Sebagaimana diketahui kondisi masyarakat Kabupaten Kulon Progo saat ini, permasalahan dan tantangan yang dihadapi di masa depan, serta dengan memperhitungkan faktor strategis dan potensi yang dimiliki oleh masyarakat, pemangku kepentingan, serta Pemerintah Kabupaten maka Visi Kabupaten Kulon Progo seperti yang tertera dalam RPJP Daerah Kabupaten Kulon Progo Tahun 2005-2025 [4].

Merujuk pada Disnakertrans Kabupaten Kulon Progo dalam melakukan proses perencanaan pembangunan, peneliti ingin mengkaji tentang apakah proses perencanan pembangunan dinas tenaga kerja dan transmigrasi kabupaten kulon progo sesuai dengan undang-undang no. 25 tahun 2004. Adapun tujuan penelitian ini adalah untuk mengetahui tentang apakah proses perencanaan pembangunan Dinas Tenaga Kerja dan Transmigrasi Kabupaten Kulon Progo sesuai dengan undang-undang no. 25 tahun 2004. Selanjutnya, manfaat penelitian ini adalah dapat memberikan gambaran apakah proses perencanaan pembangunan Dinas Tenaga Kerja dan Transmigrasi Kabupaten Kulon Progo sudah sesuai dengan undang-undang no. 25 tahun 2004 dan menjadikan salah satu bahan evaluasi disetiap instansi didaerah khususnya di Disnakertrans Kabupaten Kulon Progo.

Peneliti memulai menjelaskan tentang "apakah proses perencanaan pembangunan Dinas Tenaga Kerja dan Transmigrasi Kabupaten Kulon Progo sesuai dengan undang-undang no. 25 tahun 2004?" dengan melakukan pemetaan studi-studi terdahulu yang pernah dilakukan peneliti. Penelitian yang dilakukan [5] tentang Perencanaan Pembangunan Berbasis E-Planning Pada Dinas Pekerjaan Umum Dan Penataan Ruang Kabupaten Subang di Journal of Management Review dengan tujuan Untuk mengetahui Perencanaan Pembangunan Berbasis e-Planning di Kabupaten Subang. Yang menggunakan penelitian pendekatan kualitatif yang bersifat deskriptif, dengan hasil temuan Bahwa Perencanaan Pembangunan Berbasis e-Planning di Kabupaten Subang sesuai dengan Prinsip ideal perencanaan dikemukakan oleh Jamshid Gharajedagi dan Rusell L. Ackoff. Selain daripada itu transparansi dinilai masih semu. Hal ini disebutkan karena system masih dalam proses pengembangan. Berkesinambungan, bahwa beberapa usulan masih dalam bentuk tertulis, tidak seluruh pengajuan di ajukan dalam sistem elektronik. Selama ini pemerintah Kabupaten Subang memfasilitasi SIRENDA sebagai situs yang menampung seluruh ajuan masyarakat, namun seluruh ide dan aspirasi tidak dimuat secara langsung.

Tentang Peran Dinas Tenaga Kerja Kota Batam Terhadap Perencanaan Pembangunan Ketenagakerjaan Dalam Meningkatkan Kompetensi Tenaga Kerja Pada Era Masyarakat Ekonomi Asean (MEA) di jurnal Menara Ilmu dengan tujuan Untuk mendeskripsikan dampak yang ditimbulkan dari pemberlakuan Masyarakat Ekonomi Asean (MEA) bagi sektor Ketenagakerjaan dan mendeskripsikan strategi perencanaan pembangunan ketenagakerjaan yang dirancang oleh Dinas Tenaga Kerja Kota Batam dalam meningkatkan Kompetensi tenaga kerja pada Era Masyarakat Ekonomi Asean serta memetakan faktor-faktor yang menjadi penghambat perencanaan pembangunan ketenagakerjaan, yang 
dialami oleh Dinas Tenaga Kerja Kota Batam. Menemukan hasil temuan Menunjukan bahwa Integrasi MEA ini membawa dampak positif bagi sektor tenaga Kerja. Terdapat kesempatan yang sangat besar bagi para pencari kerja, karena banyak tersedia lapangan kerja dengan berbagai kebutuhan keahlian yang beraneka ragam. Selain itu, akses untuk pergi keluar negeri dalam rangka mencari pekerjaan menjadi lebih mudah bahkan bisa jadi tanpa ada hambatan tertentu. Untuk itu, sebagai leading sector pengembangan kompetensi tenaga kerja, Dinas Tenaga Kerja Kota Batam bertanggung jawab untuk mempercepat peningkatan kompetensi tenaga kerja dengan menjalankan program peningkatan kompetensi yang terintegrasi, untuk menghasilkan tenaga kerja yang berkualitas, produktif, efisien, dan efektif dalam melakukan tugas dan pekerjaannya sehingga mampu bersaing dalam era Masyarakat Ekonomi Asean ini [6].

Penelitian tentang peranan pemerintah daerah dalam perencanaan pembangunan daerah di JISIP: Jurnal IImu Sosial dan Ilmu Politik yang menggunakan Metode penelitian yang digunakan adalah metode kualitatif yaitu penelitian kualitatif yang menemukan hasil penelitian Peranan pemerintah daerah dalam perencanaan pembangunan di Distrik Manatuto yang ada pada umumnya proses perencanaan dilakukan oleh komonitas masyarakat serta pemimpin lokalnya, dengan penentuan strategi pembangunan daerahnya dan dirumuskan dengan memperhatikan kondisi dan potensi lingkungan yang dimiliki di daerah. Baik yang sudah dapat dilaksanakan maupun belum. Peranan pemerintah daerah dan komonitas masyarakat di daerah dalam pelaksanaan perencanaan pembangunan daerah itu berjalan dengan baik apabila dilihat dari segi penyusunan dokumen rencananya. Karena dokumen rencana akan menyangkut smeua bidang-bidang atau aspek-aspek perencanaan yang dibutuhkan oleh masyarakat umum [7].

Penelitian tentang analisis konsistensi dokumen perencanaan pembangunan daerah di kabupaten maluku tengah studi kasus RPJMD, RKPD, RENSTRA dan RENJA Dinas Kesehatan tahun 2013-201) yang dilakukan [8] yang bertujuan untuk menganalisis inkonsistensi dokumen perencanaan pembangunan daerah pada Dinas Kesehatan di Kabupaten Maluku Tengah tahun 2013-2017 yang meliputi konsistensi dokumen RPJMD-Renstra, RPJMD-RKPD, RKPD-Renja dan RenstraRenja serta faktor-faktor yang mempengaruhi inkonsistensi dokumen perencanaan. Menggunakan deskriptif kualitatif dengan pendekatan studi kasus pada dokumen perencanaan pembangunan daerah. Hasil penelitian adalah menunjukkan bahwa secara keseluruhan tingkat konsistensi dokumen perencanaan untuk program dan kegiatan operasional lebih baik jika dibandingkan dengan program dan kegiatan strategis. Tingkat konsistensi dokumen perencanaan Dinas Kesehatan terendah dihasilkan oleh Renstra-Renja yaitu hanya sebesar 16,97 \% (sangat buruk). Inkonsistensi dokumen perencanaan pada Dinas Kesehatan ini dipengaruhi oleh faktorfaktor: (1) Tahapan perencanaan yang dimulai dari penyusunan perencanaan sampai dengan evaluasi tidak dilakukan dengan baik. (2) Pimpinan kurang efektif dimana pimpinan tidak berorientasi pada tugas dan hubungan dengan bawahannya dalam penyusunan dokumen perencanaan sehingga berbagai permasalahan yang dihadapi dalam penyusunan dokumen tidak dapat diatasi. (3) Rendahnya kualitas SDM perencana karena rendahnya kompetensi aparatur perencana sehingga mempengaruhi konsistensi dokumen perencanaan. (4) Egovernment yang berupa aplikasi perencanaan belum dilaksanakan sehingga dokumen perencanaan yang disusun tidak terintegrasi dan terkoneksi. 5. Koordinasi secara interen dan eksteren dalam penyusunan dokumen perencanaan belum dilakukan dengan baik.

\section{TINJAUAN PUSTAKA}

\subsection{Dinas Tenaga Kerja dan Transmigrasi}

Berdasarkan Peraturan Bupati Kulon Progo Nomor: 59 Tahun 2016 tentang Kedudukan, susunan, organisasi,fungsi, dan tugas, serta tata kerja pada Dinas Tenaga Kerja dan Transmigrasi, mempunyai fungsi penyelenggaraan urusan Pemerintahan Daerah dan tugas pembantuan di bidang tenaga kerja dan transmigrasi. penyelenggaraan fungsi tersebut, Disnakertrans mempunyai tugas [9]: Menyelenggarakan pengelolaan bidang hubungan industrial dan perlindungan tenaga kerja;

1. Menyelenggarakan pengelolaan bidang pengembangan dan penempatan tenaga kerja;

2. Menyelenggarakan pengelolaan bidang transmigrasi; dan

3. Menyelenggarakan pengelolaan ketatausahaan.

Dengan mempertimbangkan visi Kepala Daerah serta guna mengatasi permasalahan 
ketenagakerjaan dan ketransmigrasian, maka Visi Dinas Tenaga Kerja dan Transmigrasi Kabupaten Kulon Progo Tahun 2017-2022 adalah "Terwujudnya Tenaga Kerja yang kompeten, dan iklim kerja yang kondusif". Terwujudnya tenaga kerja yang kompeten adalah tenaga kerja yang memiliki etos kerja tinggi, berketrampilan, profesional, produktif,kreatif, dan inovatif. Terwujudnya iklim kerja yang kondusif artinya adalah suatu kondisi harmonis dan dinamis dalam hubungan kerja yang mengandung unsur-unsur sebagai berikut:

1. Terjaminnya hak semua pihak (pekerja dan pengusaha),

2. Terwujudnya tata niaga yang berkeadilan, yaitu dengan meningkatnya fungsi pemerintah daerah, bisnis yang beretika dan pemberdayaan konsumen.

3. Meningkatkan kesejahteraan dan produktifitas tenaga kerja, serta kemajuan perusahaan.

\subsection{Undang-Undang No. 25 Tahun 2004}

Undang-Undang Dasar Negara Republik Indonesia Tahun 1945 yang merupakan landasan konstitusional penyelenggaraan negara, dalam waktu relatif singkat (19992002), telah mengalami 4 (empat) kali perubahan. Dengan berlakunya amandemen Undang-Undang Dasar Negara Republik Indonesia Tahun 1945, telah terjadi perubahan dalam pengelolaan pembangunan, yaitu:

1. Penguatan kedudukan lembaga legislatif dalam penyusunan Anggaran Pendapatan dan Belanja Negara (APBN);

2. ditiadakannya Garis-garis Besar Haluan Negara (GBHN) sebagai pedoman penyusunan rencana pembangunan Nasional; dan

3. diperkuatnya Otonomi Daerah dan desentralisasi pemerintahan dalam Negara Kesatuan Republik Indonesia.

GBHN yang ditetapkan oleh Majelis Permusyawaratan Rakyat Republik Indonesia (MPR RI) berfungsi sebagai landasan perencanaan pembangunan Nasional sebagaimana telah dilaksanakan dalam praktek ketatanegaraan selama ini. Ketetapan MPR RI ini menjadi landasan hukum bagi Presiden untuk dijabarkan dalam bentuk Rencana Pembangunan Lima Tahunan dengan memperhatikan secara sungguh-sungguh saran Dewan Perwakilan Rakyat Republik Indonesia (DPR RI), yang selanjutnya Pemerintah bersama DPR RI menyusun APBN. Perubahan Undang-Undang Dasar Negara Republik Indonesia Tahun 1945 yang mengatur bahwa Presiden dipilih secara langsung oleh rakyat dan tidak adanya GBHN sebagai pedoman Presiden untuk menyusun rencana pembangunan maka dibutuhkan pengaturan lebih lanjut bagi proses perencanaan pembangunan Nasional.

Dengan berlakunya Undang-Undang Nomor 22 Tahun 1999 tentang Pemerintahan Daerah, penyelenggaraan Otonomi Daerah dilaksanakan dengan memberikan kewenangan yang luas, nyata, dan bertanggung jawab kepada Daerah. Pemberian kewenangan yang luas kepada Daerah memerlukan koordinasi dan pengaturan untuk lebih mengharmoniskan dan menyelaraskan pembangunan, baik pembangunan Nasional, Pembangunan Daerah maupun pembangunan antar daerah.

Berdasarkan pertimbangan di atas, perlu dibentuk Undang-Undang yang mengatur tentang Sistem Perencanaan Pembangunan Nasional. Undang-Undang ini mencakup landasan hukum di bidang perencanaan pembangunan baik oleh Pemerintah Pusat maupun Pemerintah Daerah. Dalam UndangUndang ini ditetapkan bahwa Sistem Perencanaan Pembangunan Nasional adalah satu kesatuan tata cara perencanaan pembangunan untuk menghasilkan rencana pembangunan dalam jangka panjang, jangka menengah, dan tahunan yang dilaksanakan oleh unsur penyelenggara pemerintahan di pusat dan Daerah dengan melibatkan masyarakat.

\subsection{Proses Tahapan Perencanaan Pembangunan}

Sistem perencanaan pembangunan nasional dalam undang-undang ini mencakup lima pendekatan dalam seluruh rangkaian perencanaan, yaitu: (Halim, 2014) lima pendekatan politik, kemudian teknokratik, selanjutnya partisipatif, kemudian atas-bawah (top-down); dan juga bawah-atas (bottom-up).

Pendekatan politik memandang bahwa pemilihan Presiden/Kepala Daerah adalah proses penyusunan rencana, karena rakyat pemilih menentukan pilihannya berdasarkan programprogram pembangunan yang ditawarkan masing-masing calon Presiden/Kepala Daerah. Oleh karena itu, rencana pembangunan adalah penjabaran dari agenda-agenda pembangunan yang ditawarkan Presiden/Kepala Daerah pada saat kampanye ke dalam rencana pembangunan jangka menengah.

Perencanaan dengan pendekatan teknokratik dilaksanakan dengan menggunakan metode dan kerangka berpikir ilmiah oleh lembaga atau satuan kerja yang secara fungsional bertugas untuk itu. Perencanaan dengan pendekatan partisipatif dilaksanakan dengan melibatkan semua pihak yang berkepentingan (stakeholders) terhadap pembangunan. Pelibatan mereka adalah untuk mendapatkan aspirasi dan menciptakan rasa memiliki. 
Sedangkan pendekatan atas-bawah dan bawahatas dalam perencanaan dilaksanakan menurut jenjang pemerintahan. Rencana hasil proses atas-bawah dan bawah-atas diselaraskan melalui musyawarah yang dilaksanakan baik di tingkat Nasional, Provinsi, Kabupaten/Kota, Kecamatan, dan Desa.

Perencanaan pembangunan terdiri dari empat (4) tahapan yakni:

(1) penyusunan rencana;

(2) penetapan rencana;

(3) pengendalian pelaksanaan rencana; dan

(4) evaluasi pelaksanaan rencana.

Keempat tahapan diselenggarakan secara berkelanjutan sehingga secara keseluruhan membentuk satu siklus perencanaan yang utuh. Tahap penyusunan rencana dilaksanakan untuk menghasilkan rancangan lengkap suatu rencana yang siap untuk ditetapkan yang terdiri dari 4 (empat) langkah.

Langkah pertama adalah penyiapan rancangan rencana pembangunan yang bersifat teknokratik, menyeluruh, dan terukur. Langkah kedua, masing-masing instansi pemerintah menyiapkan rancangan rencana kerja dengan berpedoman pada rancangan rencana pembangunan yang telah disiapkan. Langkah berikutnya adalah melibatkan masyarakat (stakeholders) dan menyelaraskan rencana pembangunan yang dihasilkan masing-masing jenjang pemerintahan melalui musyawarah perencanaan pembangunan. Sedangkan langkah keempat adalah penyusunan rancangan akhir rencana pembangunan.

\section{METOdOLOgI PENELITIAN}

Metode penelitian yang digunakan adalah kualitatif deskriptif. Adapun lokasi penelitian ini dilakukan di Disnakertrans Kabupaten Kulonprogo. Fokus dalam penelitian ini adalah apakah proses perencanaan pembangunan di Diskertrans kabupaten kulon progo sesuai dengan undang-undang no. 25 tahun 2004?. Dalam pengumpulan data penelitian dilakukan dengan wawancara, observasi langsung, dan dokumentasi, dan dokumen-dokumen lamporan. Undang-undang-undang.

\section{HASIL DAN PEMBAHASAN}

\subsection{Penyusunan Rencana dan Penetapan Perencanaan Pembangunan Disnakertrans Kabupaten Kulon Progo}

Rencana Strategis Organisasi Perangkat Daerah (OPD) merupakan dokumen perencanaan SKPD untuk periode 5 (lima) tahun. Renstra SKPD memuat tujuan, strategi, kebijakan, program dan kegiatan Disnakertrans Kabupaten Kulon Progo. Renstra SKPD disusun sesuai dengan tugas dan fungsi SKPD serta berpedoman pada RPJM Daerah dan bersifat indikatif. Selain memperhatikan tugas dan fungsi, penyusunan rencana strategi ini juga melalui Forum Discusion (FGD) dihadiri narasumber dari kalangan akademisi, stakeholder terkait, mitra kerja serta lembaga lembaga yang langsung maupun tidak langsung memberikan masukan, saran dan kritik agar Dinas Tenaga Kerja dan Transmigrasi dalam menghadapi tantangan dan masalah pada masa mendatang dengan baik dan lancar.

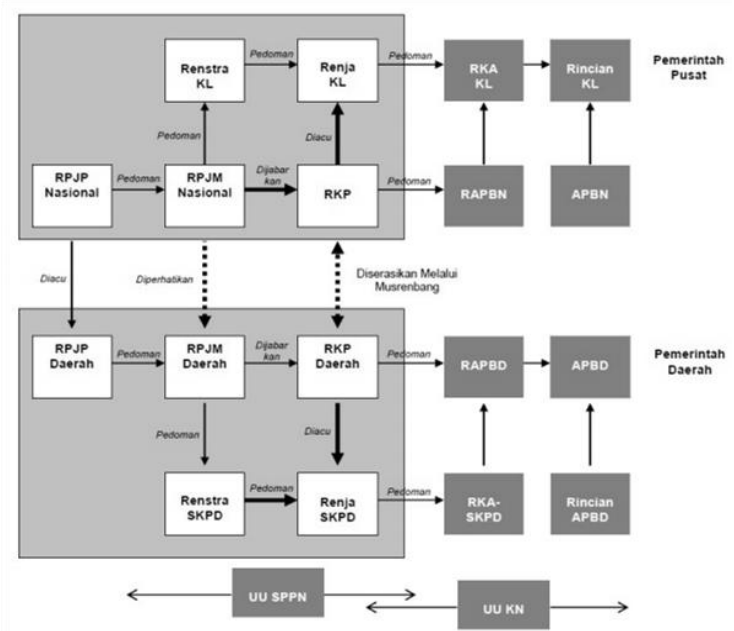

Gambar 1. Penyusunan dan keterkaitan Renstra Disnakertrans Kabupaten Kulon Progo dengan dokumen lainnya

Dokumen Renstra SKPD disusun dengan mengacu RPJMD Kabupaten Kulon Progo Tahun 2017-2022. Hal ini dimaksudkan agar rencana pembangunan yang tertuang dalam RPJMD Kabupaten Kulon Progo sesuai tugas fungsi Dinas Tenaga Kerja dan Transmigrasi dapat melaksanakan kewenangannya sesuai dengan tujuan yang telah ditetapkan dalam RPJMD. Di samping itu dalam menyusun renstra Disnakertrans Kabupaten Kulon Progo juga mengacu pada renstra Kementrian/Lembaga terkait dan Renstra Provinsi. Dengan demikian diharapkan hasil akhir dari proses penyusunan dokumen Renstra menghasilkan dokumen rencana yang sinergis dan terpadu dalam aspek perencanaan pembangunan daerah dengan harapan dalam implementasinya memperoleh hasil yang tepat dan terarah dalam mendukung tujuan daerah khususnya nasional umumnya. Diperkuat juga dengan hasil wawancara dengan ibu A.S yang mengatakan:

"Sebelum adanya pembangunan untuk masyarakat memang disini disetiap OPD khususnya Disnaker Kulon Progo tentu 
diarahkan melalui Renstra yang mengacu pada RPJMD Kab. Kulon Progo mas dan setiap tahunnya jugadijabarkan dalam Renja SKPD mba,mas ..."

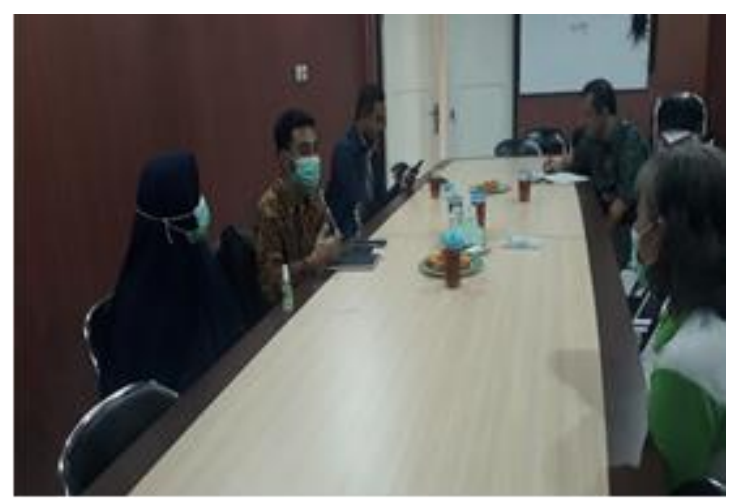

Gambar 2. Interview dengan Bu A.S selaku pegawai Disnakertrans Kabupaten Kulon Progo

Dalam hal ini secara tegas hasil dari wawancara menunjukan secara operasional Renstra SKPD setiap tahunnya dijabarkan dalam Renja SKPD yang merupakan dokumen perencanaan SKPD untuk periode satu tahun.

Adapun dalam proses pembangunan juga diperuntukan dalam misi ketiga di Disnakertrans yang mana bertujuan untuk meningkatkan perlindungan dan pengawasan ketenagakerjaan sesuai kewenangannya Dinas Tenaga Kerja dan Transmigrasi Kabupaten Kulon Progo hanya melaksanakan perlindungan ketenagakerjaan sehubungan dengan fungsi pengawasan merupakan kewenangan pemerintah provinsi dalam hal ini Dinas Tenaga Kerja dan Transmigrasi DIY. Dengan demikian sasaran Disnakertrans Kabupaten Kulon Progo telah sejalan dengan kebijakan bidang ketenagakerjaan dan bidang ketransmigrasian Disnakertrans DIY. Pada program peningkatan ketrampilan dan kompetensi dilakukan koordinasi antara kabupaten dengan provinsi dalam pemilihan kejuruan pelatihan agar sesuai dengan kebutuhan dan karakteristik Kabupaten Kulon Progo serta penentuan peserta pelatihan berbasis kemasyarakatan.

Pada program hubungan industrial dan perlindungan tenaga kerja, walaupun kewenangan pengawasan perusahaan berada di provinsi tetap ada koordinasi dengan kabupaten dalam pelaksanaan tugas fungsi masingmasing. Dalam menyongsong pembangunan bandara, Kementerian Tenaga Kerja bekerja sama dengan Kementrian Perhubungan melalui Direktorat Jenderal Perhubungan Udara melalui pelatihan kebandaraudaraan yang diselenggarakan di UPTD Balai Latihan Kerja Disnakertrans Kabupaten Kulon Progo dan pengiriman peserta pelatihan ke Sekolah Tinggi Penerbangan Indonesia Curug. Dalam hal ini juga dijelaskan dalam hasil observasi langsung, dan juga merupakan program utama pula di Disnakertrans kabupaten Kulon Progo.

\subsection{Pendekatan pelaksanaan Perencanaan Pembangunan}

Adapun dalam kegiatan proses perencanaan pembangunan di Disnakertrans dilakukan sesuai undangundang no. 25 tahun 2004 sebagaiaman dalam pendekatan politik, teknokratik, selanjutnya partisipatif yang dilakukan adalah melalui berbagai pertemuan seperti musyawarah desa, dan hingga melakukan proposal program yang diinginkan oleh masyarakat melalui LPMD. Adapun secara top down dan bottom up juga dilakukan oleh Disnakertrans Kabupaten Kulon Progo.

Diketahui pendekatan top down planning ini adalah model perencanaan yang dilakukan dari atasan yang ditujukan kepada bawahannya dimana yang mengambil keputusan adalah atasan sedangkan bawahan hanya sebagai pelaksana saja. Dalam pengertian lain terkait dengan pemerintahan, perencanaan top down planning atau perencanaan atas adalah perencanaan yang dibuat oleh pemerintah ditujukan kepada masyarakat dimana masyarakat sebagai pelaksana [10]. Hal ini, dilakukan oleh Disnakertrans melalui koordinasi dengan Bappeda Kulon Progo untuk menyaring semua aspirasi masyarakat yang kemudian ditentukan oleh pemerintah daerah untuk menindaklanjuti program yang diinginkan oleh masyarakat kulon progo.

Kemudian button up planning 
merupakan perencanaan yang dibuat berdasarkan kebutuhan, keinginan dan permasalahan yang dihadapi oleh bawahan bersama-sama dengan atasan menetapkan kebijakan atau pengambilan keputusan dan atasan juga berfungsi sebagai fasilitator. Sedangkan dalam pengertian dibidang pemerintahan, button up planning atau perencanaan bawah adalah perencanaan yang disusun berdasarkan kebutuhan mereka sendiri dan pemerintah hanya sebagai fasilitator[11].

Jika dilihat dari hasil observasi langsung, dan interview. Kegiatan dalam pelaksanaan belum sepenuhnya dilakukan melalui button up dikarenakan kegiatan ataupun program dalam proses pembangunan ini tidak dilihat dari kebutuhan masyarakat secara sepenuhnya, hal ini dibuktikan dari hasil wawancara dengan pegawai Disnakertrans kulon progo secara langsung dan diperkuat dengan beberapa dokumen yang didapatkan dari pihak dinas.

\section{KESIMPULAN DAN SARAN}

Hasil temuan dalam penelitian ini menunjukan bahwa proses perencanaan pembangunan di Dinas Tenaga Kerja dan Transmigrasi Kabupaten Kulon Progo sudah sesuai dengan undang-undang No. 25 Tahun 2004, hal ini sudah dibuktikan dengan proses tahapan awal dimulai dari penyusunan dokumen Renstra SKPD disusun dengan mengacu RPJMD Kabupaten Kulon Progo Tahun 2017-2022 yang dimulai dari penyusunan rencana, penetapan rencana, pengendalian pelaksanaan rencana; dan evaluasi pelaksanaan rencana. Namun dalam pelaksanaan secara konkrit memang belum secara merata di daerah Kulon Progo.

\section{DAFTAR PUSTAKA}

[1] Pelayananpublik. id pelayananpublik.id, "Arti Perencanaan (Planning), Manfaat Hingga Macamnya," Pelayanan Publik, 2020.

https://pelayananpublik.id/2020/01/22/ arti-perencanaan-planning-manfaathingga-macamnya/ (accessed Dec. 03, 2020).

[2] D. Deviyanti, "Studi Tentang Partisipasi Masyarakat Dalam Pembangunan Di
Kelurahan Karang Jati Kecamatan Balikpapan Tengah," EJournal Adm. Negara, vol. 1, no. 2, pp. 380-394, 2013.

[3] Kemenpppa. go. id kemenpppa.go.id, "Bab Xi Sistem Pendukung Manajemen Pembangunan Nasional." www.kemenpppa.go.id, 2004, [Online]. Available:

https://www.kemenpppa.go.id/lib/uploa ds/list/b162d-0211-buku-ii-bab-xi.pdf.

[4] nakertrans. kulonprogokab. go. id nakertrans.kulonprogokab.go.id,

"DISNAKERTRANS - Visi dan Misi," 2019.

https://nakertrans.kulonprogokab.go.id/ detil/2058/visi-dan-misi (accessed Dec. 03, 2020).

[5] D. Andani, "Perencanaan Pembangunan Berbasis E-Planning Pada Dinas Pekerjaan Umum Dan Penataan Ruang Kabupaten Subang," J. Manag. Rev., vol. 4, no. 1 , Art. no. 1, Jan. 2020, doi: 10.25157/mr.v4i1.3015.

[6] R. Riyanda and A. Dula, "Peran Dinas Tenaga Kerja Kota Batam Terhadap Perencanaan Pembangunan Ketenagakerjaan Dalam Meningkatkan Kompetensi Tenaga Kerja Pada Era Masyarakat Ekonomi Asean (MEA)," Menara Ilmu, vol. 14, no. 2, Art. no. 2, Jul. 2020, doi: 10.31869/mi.v14i2.1908.

[7] A. Soares, R. Nurpratiwi, and M. Makmur, "Peranan Pemerintah Daerah Dalam Perencanaan Pembangunan Daerah," J. Ilmu Sos. Dan Ilmu Polit., vol. 4, no. 2, Art. no. 2, Aug. 2015, Accessed: Dec. 03, 2020. [Online]. Available:

https://publikasi.unitri.ac.id/index.php/f isip/article/view/102.

[8] S. Hajara, "Analisis Konsistensi Dokumen Perencanaan Pembangunan Daerah Di Kabupaten Maluku Tengah (Studi Kasus Rpjmd, Rkpd, Renstra Dan Renja Dinas Kesehatan Tahun 20132017)," Universitas Gadjah Mada, 2018.

[9] nakertrans. kulonprogokab. go. id nakertrans.kulonprogokab.go.id, "DISNAKERTRANS - Tupoksi dan SDA," 2019.

https://nakertrans.kulonprogokab.go.id/ detil/2059/tupoksi-dan-sda (accessed Dec. 03, 2020).

[10] O. F. S. Kawer, M. Baiquni, Y. T. Keban, and A. Subarsono, "Implementasi Kebijakan Pembangunan Rumah Layak Huni Dengan Pendekatan Hibrida Di Kabupaten SUPIORI PROVINSI PAPUA," Sosiohumaniora, vol. 20, no. 3, Art. no. 
3, Nov. 2018, doi:

10.24198/sosiohumaniora.v20i3.18489.

[11] H. Suroso, A. Hakim, and I. Noor,

"Faktor-Faktor Yang Mempengaruhi

Partisipasi Masyarakat Dalam

Perencanaan Pembangunan Di Desa

Banjaran Kecamatan Driyorejo

Kabupaten Gresik," Wacana J. Soc.

Humanity Stud., vol. 17, no. 1, Art. no.

$1,2014$. 